Научная статья

УДК 378.115.15:34

DOI: $10.18101 / 2307-3330-2021-3-70-74$

\title{
ПУТИ ПОВЫШЕНИЯ УРОВНЯ ПРАВОСОЗНАНИЯ В СТУДЕНЧЕСКОЙ СРЕДЕ В ПЕРИОД ПАНДЕМИИ
}

\author{
(C) Кондаурова Алена Михайловна \\ преподаватель, \\ Иркутский технологический колледж имени Шампанова \\ Россия, 664050, г. Иркутск, ул. Байкальская, 255 \\ amkond@mail.ru
}

\author{
Необходимо предъявлять к ребенку твердые, \\ непререкаемые требования общества, \\ вооружать нормами поведения, чтобы он знал, \\ что можно и чего нельзя, что похвально и что наказуемо \\ A. С. Макаренко
}

\begin{abstract}
Аннотация. Мы живем в сложный период перемен вследствие распространения пандемии, которая, безусловно, затронула все сферы общественной жизни, в том числе и образование. В связи с этим у граждан произошла деформация позитивных правовых идей, убеждений, чувств, что привело к отрицательному отношению к действующему праву, законности и правопорядку. Теперь к системе профессионального образования предъявляются новые требования к применению методик и способов формирования у студентов правовой культуры. В статье рассматриваются пути повышения правосознания среди молодежи в период пандемии. С помощью анкетирования определен уровень сформированности правового сознания в студенческой среде. Выявлены причины необходимости повышения правовой культуры студентов, охарактеризованы основные формы работы с учащимися на учебных занятиях.

Ключевые слова: пандемия, правовая культура, правосознание, законопослушное поведение, педагогические технологии, учебное занятие, образование, дистанционное обучение, информационные технологии, молодежь.
\end{abstract}

\section{Для цитирования}

Кондаурова А. М. Пути повышения уровня правосознания в студенческой среде в период пандемии // Вестник Бурятского государственного университета. Образование. Личность. Общество. 2021. № 3. С. 70-74.

Мы живем в сложный период социальных преобразований вследствие пандемии. Состояние социально-политических процессов в нашей стране обусловливает новые требования к системе профессионального образования, для которой характерно отсутствие или игнорирование применения методик и способов формирования у студентов правовой культуры. Все это ведет к пробелам правовых знаний, неуважительному отношению к законам и существующему государственно-политическому устройству. Деформация правосознания, в том числе и в студенческой среде, — это явление социально-правовой действительности, которое демонстрирует искажение у граждан позитивных правовых идей, убеждений, 
чувств, установок и выражается в отрицательном отношении к действующему праву, законности и правопорядку. Формирование правосознания, особенно среди молодежи, является одним из важных условий законопослушного поведения граждан в обществе в период пандемии.

Повышение правовой культуры и законопослушного поведения студентов это целенаправленная система мер, формирующая установки патриотизма, гражданственности, уважения и соблюдения права, цивилизованных способов решения споров, профилактики правонарушений.

Повышение уровня правосознания студентов обусловлено рядом причин:

- Федеральный государственный образовательный стандарт предъявляет современные требования к результатам обучения и воспитания, так как изменения, происходящие в российском обществе, определяют новые, более четкие требования ко всей системе отечественного образования [2]. Сегодня главной целью является воспитание у учащихся активной жизненной позиции, правосознания и правовой культуры, которые формируют уважительное отношение к действующей правовой системе.

- Профилактика правонарушений в обществе, главным образом среди молодежи. Правовые знания нужны студентам не сами по себе, а как основа поведения в различных спорных ситуациях. По данным прокуратуры РФ, несовершеннолетние ежегодно совершают или участвуют в более чем 40000 преступлений. $83 \%$ совершили преступления против собственности, $8 \%$ - жизни и здоровья, более $4 \%$ - это преступления, связанные с незаконным оборотом наркотиков. Период самоизоляции, который связан с распространением новой коронавирусной инфекции, привел к увеличению числа совершаемых правонарушений несовершеннолетними гражданами и молодежью.

- Распространение новой коронавирусной инфекции. Из-за пандемии возник вопрос повышения уровня правосознания среди студентов. Перед на дистанционное обучение снизил его эффективность. Часть студентов достаточно эффективно использовала информационные технологии для обучения и прохождения различных онлайн-курсов. Но большинство обучающихся не смогло освоить учебный процесс в силу плохой самоорганизованности и недостаточности информационной поддержки. Вследствие снижения эффективности образовательных программ происходит и упадок уровня правосознания. В этот непростой период часть граждан перестала видеть смысл в соблюдении правовых норм. Происходит снижение уровня доверия к власти. Центром социального проектирования «Платформа» было проведено социологическое исследование, которое показало, что $61 \%$ россиян за время распространения новой коронавирусной инфекции меньше стало доверять решениям правительства и верить в способность государства помочь гражданам в период пандемии. Таким образом, доверие к власти и уважение к закону в период пандемии резко упало. В кризисные периоды необходимо повышать правосознание граждан, особенно молодежи, так как они являются фундаментом будущих социальных преобразований.

Для решения вышеперечисленных задач необходимо внедрять в систему профессионального образования приемы формирования у студентов правовой 
культуры. При этом необходима такая педагогическая технология, которая отвечала бы потребностям современного состояния развития общества и особенностям обучения в период пандемии. В реалиях современности недостаточно иметь юридическую грамотность, а важно правильно ее использовать при разрешении различных спорных жизненных ситуаций [3].

В целях выявления уровня правосознания в сентябре 2021 г. на базе ГАПОУ ИО «Иркутский технологический колледж» было проведено анкетирование, в котором приняли участие 75 человек в возрасте от 16 до 19 лет. Студентам предлагалось ответить на следующие вопросы:

- Какие факторы влияют на процесс формирования правового сознания у молодежи? 37\% обучающихся ответили, что условия жизни и работы, $29 \%$ - организованная система обучения и воспитания влияет на формирование правового сознания молодежи, $20 \%$ - СМИ формирует правосознание молодежи, $9 \%$ на правосознание молодежи влияет проведение государственной молодежной политики. Таким образом, значительная часть студентов считает, что образование имеет большое значение для формирования правового сознания молодежи.

- Считаете ли вы, что правовое сознание молодежи в нашей стране деформировано? Больше половины респондентов считает, что деформировано, 38\% опрошенных полагают, что нет.

- Какие средства правового воздействия можно использовать в целях достижения правомерного поведения? Большинство респондентов выбрали ответ сочетание методов стимулирования и ограничения. $25 \%$ - меры наказания, $10 \%$ - методы убеждения и принуждения.

- Обязательно ли соблюдать закон? 75\% респондентов считают, что закон нужно соблюдать, $10 \%$ - нет, $15 \%$ не верят в силу закона.

- Влияет ли информационно-компьютерные технологии на правосознание молодежи? 55\% считают, что влияют, 35\% - нет, некоторые предложили свои варианты, такие как «никак не влияет» и «оно роботизирует человечество».

По результатам проведенного исследования можно прийти к выводу, что часть студентов не верит в силу законов и результативность проведения государственной политики. Но стоит отметить, что большая часть обучающихся связывает уровень правосознания с качеством образования и применением различных дистанционно-информационных технологий. Очевидно, что на учебных занятиях необходимо уделять особое внимание повышению правовой культуры и правосознанию студентов.

Основными формами такого просвещения учащихся являются уроки и классные часы по правовой тематике; использование видеоматериалов; проведение тематических игр, вечеров, диспутов, предметом которых может быть та или иная морально-правовая проблема; обсуждение книг и статей, позволяющих не только пополнить запас правовых знаний, но и сформировать свое отношение к ним; наглядная агитация (тематические стенды, папки с вырезками газетных и журнальных статей, специальная литература, видео-, аудиозаписи и т. д.); знакомство с сайтами, содержащими информацию по правовым вопросам. Стоит отметить, что на каждом учебном занятии необходимо уделять внимание таким 
вопросам, как патриотизм, нетерпимость коррупционного поведения, уважение к существующему государственно-политическому строю, важность принятия нормативно-правовых актов и правильная реализация правовых норм. Особенно эффективными являются реальные экскурсии, непосредственно связанные с правотворческой деятельностью [4].

В условиях распространения коронавирусной инфекции, переходом на дистанционное обучение и усилением режима самоизоляции особое внимание уделяется информационно-коммуникационным технологиям, созданию различных электронных пособий, использованию различных информационных площадок, таких как «КонсультантПлюс», «Гарант».

Таким образом, сущность правосознания предполагает целую систему, которая неразрывно связана с правовой культурой и правовым воспитанием. Правосознание нуждается в постоянном совершенствовании, а правовое воспитание является частью всего воспитательного процесса и обучения.

\title{
Литература
}

1. Баштаков И. П. Психология неформальных подростково-молодежных групп. Москва : Юрист, 2000. 335 с. Текст: непосредственный.

2. Вешникова Н. А., Корнеева Д. И., Провалинский Д. И. Некоторые проблемы деформации правосознания среди молодежи: взгляды и видение ситуации со стороны студенческого сообщества // Новый юридический вестник. 2021. № 6(30). С. 1-8. Текст: непосредственный.

3. Соломенко Л. Д. Формирование правовой культуры учащихся. Внимание: опыт // Практика административной работы в школе. 2003. № 3. С. 58-59. Текст: непосредственный.

4. Фарбер И. Е. Правосознание как форма общественного сознания. Москва: Юридическая литература, 1963. 205 с. Текст: непосредственный.

Статья поступила в редакиию 18.11.2021; одобрена после рецензирования 22.11.2021; принята к публикации 07.12.2021.

\section{WAYS TO INCREASE THE LEVEL OF LEGAL CONSCIOUSNESS AMONG STUDENTS DURING THE PANDEMIC}

\author{
Alena M. Kondaurova \\ teacher \\ Champanov Irkutsk Technological College \\ 255 Baikalskaya St. Irkutsk, 664050 Russia \\ amkond@mail.ru
}

We are living in a difficult period of change due to the spread of the pandemic, which, of course, has affected all spheres of public life, including education. As a result, citizens had a deformation of positive legal ideas, beliefs, feelings, which led to a negative attitude to the current law, legality and the rule of law. Now new requirements are being imposed on the system of vocational education for the application of methods and methods of forming a legal culture among students. The article discusses ways to increase the level of legal 
consciousness among young people during the pandemic. With the help of a questionnaire, the level of formation of legal consciousness in the student environment was determined. The reasons for the need to improve the legal culture of students are identified, the main forms of work with students in the classroom are characterized.

Keywords: pandemic, legal culture, legal consciousness, law-abiding behavior, pedagogical technologies, lesson, education, distance learning, information technology, youth.

The article was submitted 18.11.2021; approved after reviewing 22.11.2021; accepted for publication 07.12.2021. 